\title{
Analysis of Long-Term Meteorological Observation for Weather and Climate Fundamental Data over the Northern Tibetan Plateau
}

\author{
Fangfang Huang ${ }^{1,2}$ and Weiqiang $\mathrm{Ma}^{1,3,4}$ \\ ${ }^{1}$ Key Laboratory for Land Process and Climate Change in Cold and Arid Regions, \\ Cold and Arid Region Environmental and Engineering Research Institute, Chinese Academy of Sciences, Lanzhou 730000, China \\ ${ }^{2}$ University of Chinese Academy of Sciences, Beijing 100049, China \\ ${ }^{3}$ A Key Laboratory of Tibetan Environment Changes and Land Surface Processes, Institute of Tibetan Plateau Research, \\ Chinese Academy of Sciences, Beijing 100101, China \\ ${ }^{4}$ CAS Center for Excellence in Tibetan Plateau Earth Sciences, Beijing 100101, China
}

Correspondence should be addressed to Weiqiang Ma; wqma@itpcas.ac.cn

Received 9 April 2015; Accepted 3 June 2015

Academic Editor: Chung-Ru Ho

Copyright (c) 2016 F. Huang and W. Ma. This is an open access article distributed under the Creative Commons Attribution License, which permits unrestricted use, distribution, and reproduction in any medium, provided the original work is properly cited.

\begin{abstract}
Meteorological observation plays a critical role in climatic study, and in situ measurements are the foundation of meteorological observation, especially in the Tibetan Plateau, the surface of which is fairly complex. Several field stations in the Northern Tibetan Plateau, which features relatively homogeneous surface, were selected as the study area. A detailed description on the significance of site observation for climate prediction was given in this paper. Data from weather stations can be used to verify satellite data and provide parameters for initial mode field in the study of weather and climate changes. The field observation data in the Northern Tibetan Plateau from 2001 to 2013 is analyzed. The results show that in El Nino year, values of land surface temperature ( $\left.T_{s}\right)$, air temperature $\left(T_{a}\right)$ and wind speed are all greater than their mean values and that soil moisture values are lower than the averaged, while the opposite is the case in La Nina year. The warming rate in the Northern Tibetan Plateau is greater than that in global areas. The diurnal variations of $T_{s}$ and $T_{a}$ are various in different seasons and underlying surfaces, with the diurnal variations greater in spring, and less in summer and autumn. Furthermore, the diurnal variation in the area with drier underlying surface is more obvious than that in area with moist surface.
\end{abstract}

\section{Introduction}

It is well recognized that the Tibetan Plateau plays an important role in the East Asian and global climate because of its high evaluation and complex surface conditions. The land surface of the Tibetan Plateau reaches evaluations of greater than $4000 \mathrm{~m}$ above sea level, which is about a third of the height of the troposphere. It interacts with the atmosphere through radiation, sensible heat flux, and latent heat flux, and because of its topographic condition, the Tibetan Plateau exerts profound dynamical and thermal influences on Asian monsoon, the atmospheric circulation, and global climate change [1-3]. The huge heat source certainly has an effect on the vertical circulation over the plateau and its surrounding areas. The heat source can impact Chinese precipitation in summer by changing the intensity of the East Asian monsoon [4].

Decades of research on the Tibetan Plateau indicates that the plateau plays a vital part in the East Asian and global weather and climate prediction. Then the long-term meteorological observation in the plateau is essential and crucial for the research. Scientists have started to observe the atmospheric condition over the Tibetan Plateau systematically since 1970s. The first atmospheric science experiment on the Tibetan Plateau in 1979 (QXPMEX-1979) was performed by Ye and Gao. In that field experiment, the variation and distribution characteristics of each component in the land surface radiation balance and heat balance were analyzed, and the changing process of the heat source has been well understood [5-9]. Afterwards, the second atmospheric 

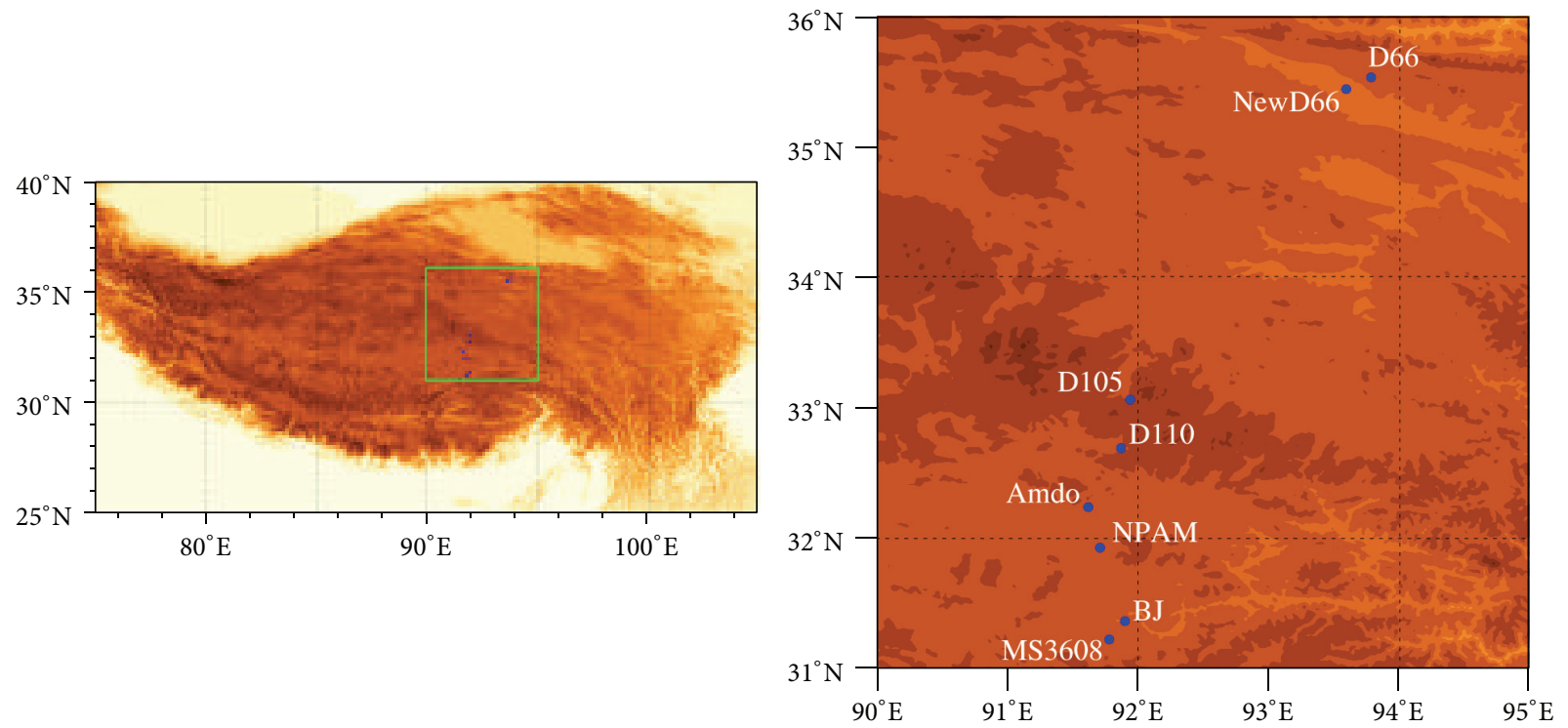

FIgURE 1: Map for the observation area and locations of stations in the Northern Tibetan Plateau.

science experiment on the Tibetan Plateau (TIPEX) was started in 1998. With the attention for the influence of the atmospheric hydrological process on the Asian monsoon increasing, the global energy and water cycle experiment (GEWEX) included the experiments called "GAME/Tibet" and "CAMP/Tibet," which mainly aimed for researching the energy exchange between land and atmosphere in the Tibetan Plateau [10]. And in order to recognize the interaction between land and atmosphere further and quantitatively, these experiments covered the observation for the solar radiation, soil temperature and soil moisture, air temperature and pressure, soil heat flux, sensible and latent heat flux, and so on. Moreover, radiosonde observation has provided amount of data for the meteorological observation. The wind speed and direction, air temperature, moisture, and pressure data in the upper air are used to judge the atmospheric stratification and circulation situation [11].

However, the Tibetan Plateau covers a vast geographic area with various landforms, and the research is largely deficient only by a few of weather stations. But the remote sensing observation features large coverage and can obtain different surface parameters simultaneously, and it makes up the deficiency for the conventional observation data. With the developing of the satellite remote sensing, using satellite data to research various weather systems over the plateau has been a popular way. Meanwhile, an important method of estimating the air temperature by satellite data has been put forward, and it benefits the research on the land-atmosphere interaction $[12,13]$. In addition, the essential data for the weather forecast and climate modeling and prediction are the land surface parameters, such as the soil temperature and moisture, reflectivity, emissivity, and roughness. Since the values of underlying surface are generally constant in current numerical models, the models are hard to reflect the reality of climate change $[14,15]$. On the other hand, the satellite remote sensing plays a unique role in terms of
TABLE 1: The basic information of all sites.

\begin{tabular}{lccc}
\hline Stations & Longitude and latitude & Elevation & $\begin{array}{c}\text { Underlying } \\
\text { surface }\end{array}$ \\
\hline NewD66 & $35.43^{\circ} \mathrm{N}, 93.59^{\circ} \mathrm{E}$ & $4465 \mathrm{~m}$ & $\begin{array}{c}\text { Alpine sparse } \\
\text { grassland }\end{array}$ \\
D105 & $33.06^{\circ} \mathrm{N}, 91.94^{\circ} \mathrm{E}$ & $5039 \mathrm{~m}$ & $\begin{array}{c}\text { Alpine meadow } \\
\text { NPAM }\end{array}$ \\
$31.93^{\circ} \mathrm{N}, 91.71^{\circ} \mathrm{E}$ & $4620 \mathrm{~m}$ & Alpine meadow \\
BJ & $31.37^{\circ} \mathrm{N}, 91.90^{\circ} \mathrm{E}$ & $4509 \mathrm{~m}$ & Alpine meadow \\
MS3608 & $31.23^{\circ} \mathrm{N}, 91.78^{\circ} \mathrm{E}$ & $4589 \mathrm{~m}$ & Alpine grassland \\
\hline
\end{tabular}

achieving the parameters on inhomogeneous surface in the plateau. The surface parameters can be retrieved by satellite data, and the new parameterization scheme from those data can be introduced in the numerical models [13]. Therefore, the accuracy of the prediction can be improved. Nevertheless, the data from satellites and models are all needed to be verified by the in situ observation data, so the meteorological observation stations on the Tibetan Plateau are essential for the weather and climate prediction.

\section{Materials and Methods}

2.1. Materials. As is shown in Figure 1, eight field weather stations $[11,16]$ spread along Qinghai-Tibet Railway and six of them are used in this paper. The characteristics of all stations are shown in Table 1 and the surface feature of the Northern Tibetan Plateau can be represented by the stations [16]. The elevations of these stations are all above 4500 meters; D66 and NewD66 stations are covered by alpine sparse grassland, located in north of the Northern Tibetan Plateau. The elevation of D105 station which is above $5000 \mathrm{~m}$ is the highest station among these stations. The experiment field in D105 station, covered by alpine meadows, is flat and wide, and some hills stand at the east of the field. Similarly, 
the experiment field in NPAM station, covered by alpine meadows, which are 15 centimeters tall, is flat and wide, and there are hills that are 100-200 meters tall that are around the field. The experiment field in BJ station, covered by alpine meadows, is flat and broad. MS3608 station, located in south of the area and covered by alpine grassland, is relatively moist.

Data applied in this study come from the observational data of the six stations, D66, NewD66, D105, NPAM, BJ, and MS3608. Daily meteorological data were obtained from the six stations and all these stations had complete records of meteorological factors from 2001 to 2013. The daily meteorological data included air temperature, land surface temperature, soil moisture, wind speed, and long-wave radiation. A few missing data (mainly in 2004, 2005 at BJ station) were estimated by averaging the value of other years observed at the same station.

2.2. Methods. Because of the poor quality data of land surface temperature observed, long-wave radiation data were used to calculate land surface temperature, and the formula is as follows:

$$
R_{\mathrm{lw}}^{\uparrow}=\left(1-\varepsilon_{s}\right) R_{\mathrm{lw}}^{\downarrow}+\varepsilon_{s} \sigma T_{s}^{4},
$$

where $R_{\mathrm{lw}}^{\uparrow}$ is the upward long-wave radiation, $R_{\mathrm{lw}}^{\downarrow}$ is the downward long-wave radiation, $T_{s}$ is the land surface temperature, $\sigma=5.67 \times 10^{-8} \mathrm{~W} \cdot \mathrm{m}^{-2} \mathrm{~K}^{-4}$ is Boltzmann constant, and $\varepsilon_{s}$ is land emissivity. From (1) we can see that $T_{s}$ is affected by the upward long-wave radiation $\left(R_{\mathrm{lw}}^{\uparrow}\right)$, the downward long-wave radiation $\left(R_{\mathrm{lw}}^{\downarrow}\right)$, and land emissivity $\left(\varepsilon_{s}\right)$. The influences of these three factors on $T_{s}$ have been discussed in some researches $[17,18]$. The upward and downward longwave radiation in this study were measured by radiation instruments in all stations. $\varepsilon_{s}$ of each station changes along with seasons. The influence of $\varepsilon_{s}$ was considered in this study. Normalized differential vegetation index (NDVI) was applied to calculate $\varepsilon_{s}$ in all sites, and the values were fluctuant from 0.92 to 0.98 . This result is consistent with the conclusion drawn by $\mathrm{He}$ et al. [19]. The formula used for calculating $\varepsilon_{s}$ was proposed by Van De Griend and Owe in 1993 [20]:

$$
\varepsilon_{s}=1.0094+0.047 \ln (\mathrm{NDVI}) .
$$

In addition, the data quality of other factors was proved to be good for the study, so the observed data were used to analyze the long-term changes and climate prediction.

\section{Results}

3.1. In Situ Measurements. Generally, the first-hand data for meteorology are provided by in situ measurements, and these data are widely used to validate the satellite data and model data for studying climate changes. For example, in situ measurements are compared with air temperature data estimated from the MODIS land surface data to verify the use of MODIS data for studying the spatial distribution of the air temperature by Sun et al. [21]. Three land areas covered by MODIS sinusoidal tile h26v04 (mountain area, average elevation 5002000 meters), h26v05 (high mountain area, average elevation
2000-5000 meters), and h27v05 (plain area, average elevation 0-500 meters) were selected. Figure 2 shows the correlation of the estimated and measured air temperature. The in situ observations of air temperature are in good agreement with the estimated values from MODIS, with $R^{2}$ greater than 0.95 in all areas. In addition, the Mean Absolute Deviation (MAD) values of the estimated air temperature on the three areas are all lower than $2 \mathrm{~K}$, and the Root-Mean-Square Error (RMSE) value in $\mathrm{h} 27 \mathrm{v} 05$ area $(1.84 \mathrm{~K})$ is the lowest. According to Sun, the fact that the terrain in this area is relatively flat is the possible reason. This example has excellently shown that in situ measurements play a significant role in the validation of remote sensing data. And then, another example will prove the importance of weather station measurements for the weather and climate prediction. In recent years, it has been in the spotlight that numerical models are widely introduced to study the climate change, and hypotheses in models are based on observational facts. Radiosonde data can reflect the thermodynamic structure in the upper air. For example, Boos and Kuang [22] considered that the dominant control of the South Asian monsoon was the orographic insulation, and they demonstrated the hypothesis using numerical models. Before building the hypothesis and testing the models, radiosonde data were used to analyze the thermodynamic structure in the upper air. As is shown in Figure 3, the thermodynamic structure over Indian and Tibetan stations was accurately analyzed. Figure 3(a) shows the equivalent potential temperature within $25 \mathrm{hPa}$ of the surface at radiosonde sites over and around the Tibetan Plateau. Figure 3(b) presents the daily mean profiles of temperature. Dashed lines are dry adiabats from the lowest sounding level up to the lifted condensation level and moist pseudoadiabats thereafter. Figure 3(c) represents the mean temperature difference between the Indian and Tibetan Plateau sites, with positive values denoting air that is warmer over Indian sites. The atmospheric conditions in the upper air were accurately analyzed by observational data, and reasonable hypotheses could be proposed. Based on the meteorological observation, the numerical simulated results are more dependable and accurate for the weather forecasting and climate prediction.

3.2. Long-Term Meteorological Observations. As shown in Table 2, the land surface temperature $\left(T_{s}\right)$ and air temperature $\left(T_{a}\right)$ in all stations show uptrend along with time, except for $T_{s}$ in NPAM in autumn, which show a decreasing trend with the seasonal rate $0.07^{\circ} \mathrm{C}$. In NewD66 and D105, the annual increase rates of $T_{s}$ are greater than that of $T_{a}$, and it means that the uptrend of $T_{s}$ is more obvious than that of $T_{a}$ in the north part of the Northern Tibetan Plateau. In spring and winter, the increasing trends of $T_{s}$ are more obvious, while, in summer and autumn, the rising trends of $T_{a}$ are greater than that of $T_{s}$. In BJ and MS3608, which are located in the south part of the Northern Tibetan Plateau, the annual increase rates of $T_{a}$ are greater than that of $T_{s}$. The uptrends of $T_{a}$ are remarkable in spring and summer, and the rising tendency of $T_{s}$ and $T_{a}$ in $\mathrm{BJ}$ is more apparent than that in MS3608. However, in NPAM, the annual increasing rates of $T_{s}$ and $T_{a}$ are both $0.01^{\circ} \mathrm{C} / \mathrm{a}$, and the warming trend 
TABLE 2: The annual and seasonal linear trend of $T_{s}$ and $T_{a}$ in all sites.

\begin{tabular}{lcccccccccc}
\hline & \multicolumn{2}{c}{ Annual } & \multicolumn{2}{c}{ Spring } & \multicolumn{2}{c}{ Summer } & \multicolumn{2}{c}{ Autumn } & \multicolumn{2}{c}{ Winter } \\
& $T_{s}$ & $T_{a}$ & $T_{s}$ & $T_{a}$ & $T_{s}$ & $T_{a}$ & $T_{s}$ & $T_{a}$ & $T_{s}$ & $T_{a}$ \\
\hline NewD66 & 0.12 & 0.03 & 0.11 & 0.04 & 0.02 & 0.08 & 0.01 & 0.08 & 0.09 \\
D105 & 0.12 & 0.02 & 0.04 & 0.02 & 0.02 & 0.09 & 0.07 & 0.09 & 0.05 & 0.01 \\
NPAM & 0.01 & 0.01 & 0.01 & 0.02 & 0.01 & 0.07 & -0.07 & 0.05 & 0.01 & 0.01 \\
BJ & 0.07 & 0.10 & 0.07 & 0.14 & 0.03 & 0.13 & 0.002 & 0.07 & 0.11 & 0.07 \\
MS3608 & 0.01 & 0.03 & 0.02 & 0.06 & 0.06 & 0.10 & 0.03 & 0.01 & 0.01 & 0.01 \\
\hline
\end{tabular}
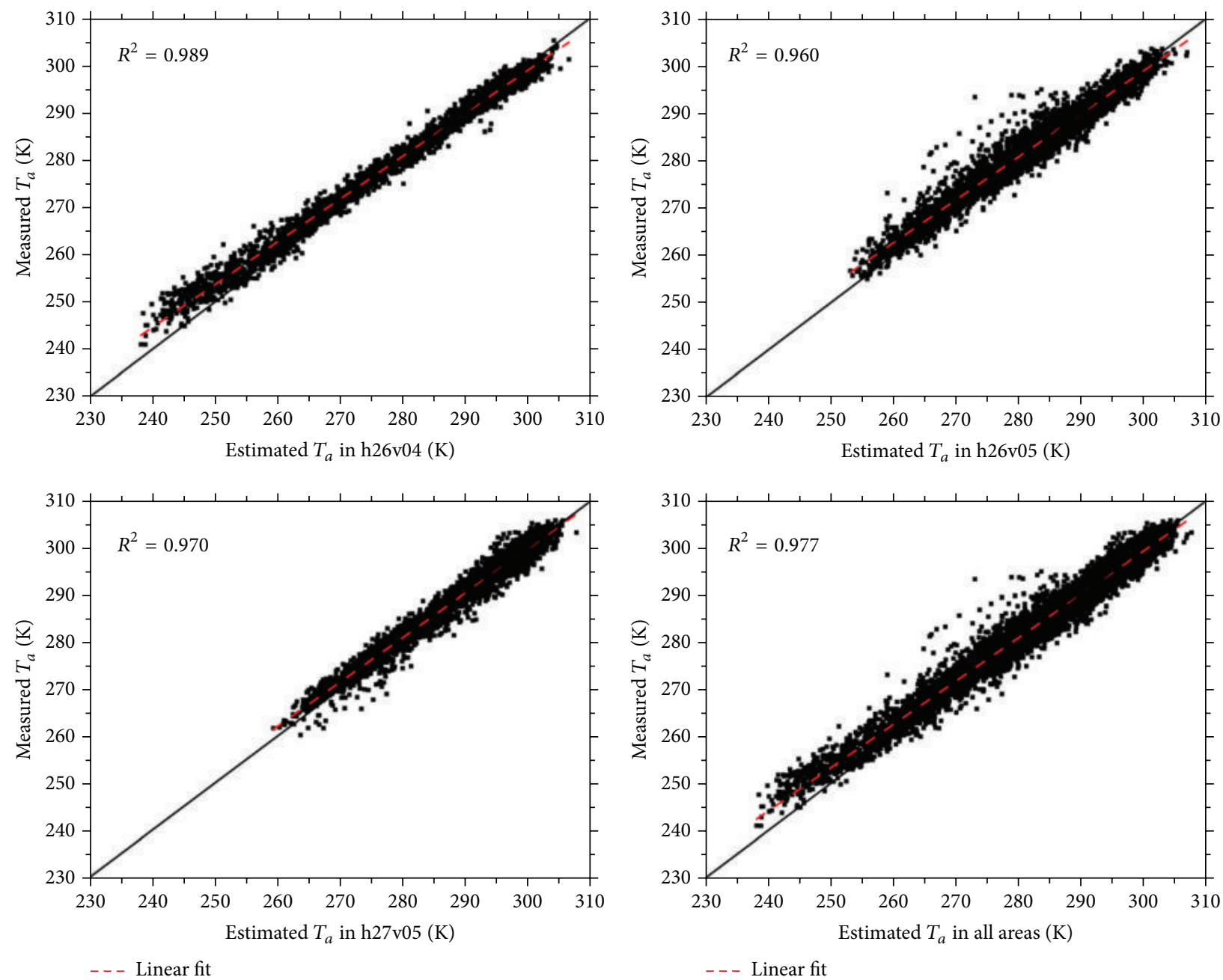

FIGURE 2: Comparisons between the estimated and measured $T_{a}$ values in three case study areas covered by the MODIS tiles h26v04, h26v05, and h27v05. (The figure is cited from Sun et al. [21].)

is not obvious compared with other stations. According to IPCC5 and some studies [23-25], the global averaged surface temperature shows a warming of $0.85^{\circ} \mathrm{C}$ over the period $1880-2012$, and over the past 60 years the rate of warming is $0.12^{\circ} \mathrm{C} / 10 \mathrm{a}$. Since 2001 , the increasing rate of $T_{a}$ in these stations is between $0.1^{\circ} \mathrm{C} / 10 \mathrm{a}$ and $1.0^{\circ} \mathrm{C} / 10 \mathrm{a}$, which means that the warming rate in the Northern Tibetan Plateau is greater than that in global areas.

Take BJ station as an example. Figure 4 shows the interannual variations of annual mean $T_{s}$ and $T_{a}$ in different seasons.
As shown in the figure, the annual increasing rates of $T_{s}$ and $T_{a}$ are $0.07^{\circ} \mathrm{C} / \mathrm{a}$ and $0.10^{\circ} \mathrm{C} / \mathrm{a}$, separately. $T_{s}$ and $T_{a}$ have been climbing since 2001, and the change trend of $T_{a}$ always keeps pace with that of $T_{s}$, but the uptrend of $T_{a}$ is more obvious than that of $T_{s}$. The warming rate of $\mathrm{BJ}$ is $1.0^{\circ} \mathrm{C} / 10$ a since 2001 , which is almost ten times compared to that in global range. The seasonal rising rates of $T_{s}$ are $0.07^{\circ} \mathrm{C}, 0.03^{\circ} \mathrm{C}, 0.002^{\circ} \mathrm{C}$, and $0.11^{\circ} \mathrm{C}$, respectively, in spring, summer, autumn, and winter, while those of $T_{a}$ are $0.14^{\circ} \mathrm{C}, 0.13^{\circ} \mathrm{C}, 0.07^{\circ} \mathrm{C}$, and $0.07^{\circ} \mathrm{C}$. The air temperatures show warming trend in all seasons, 


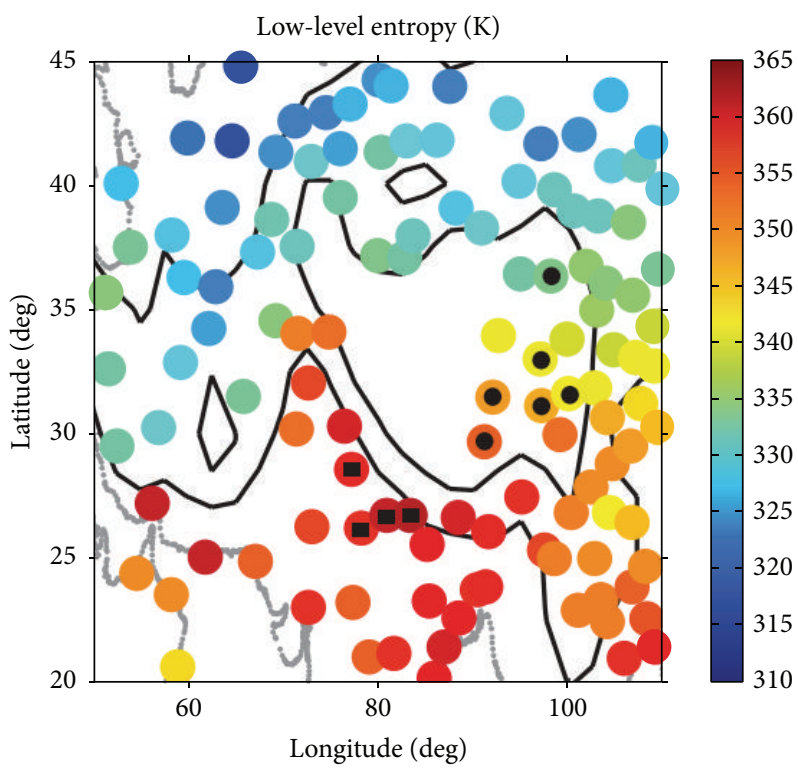

(a)

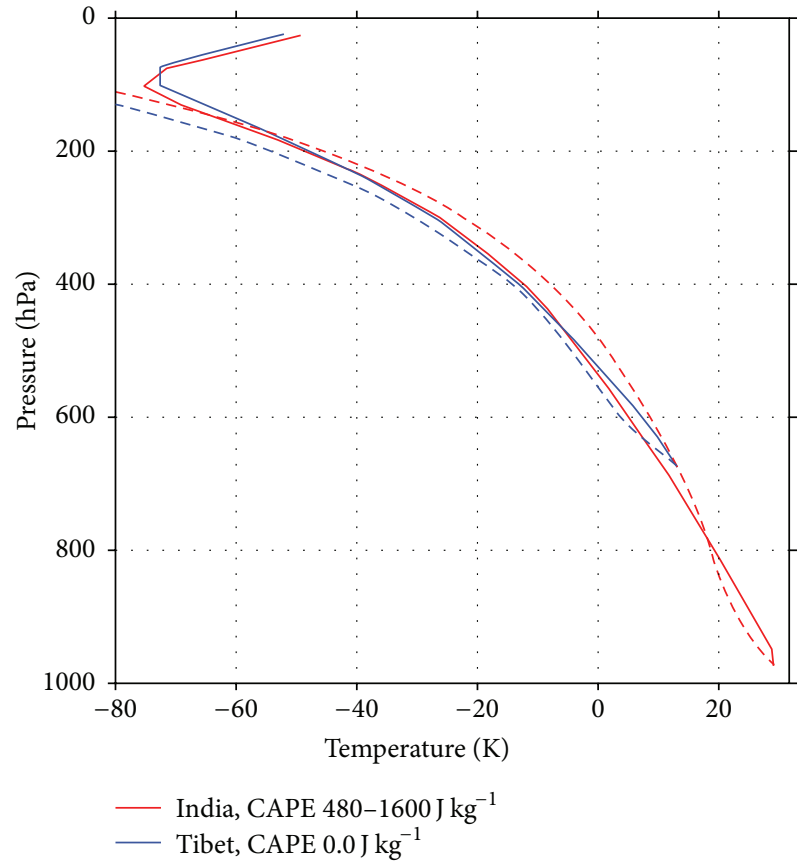

(b)

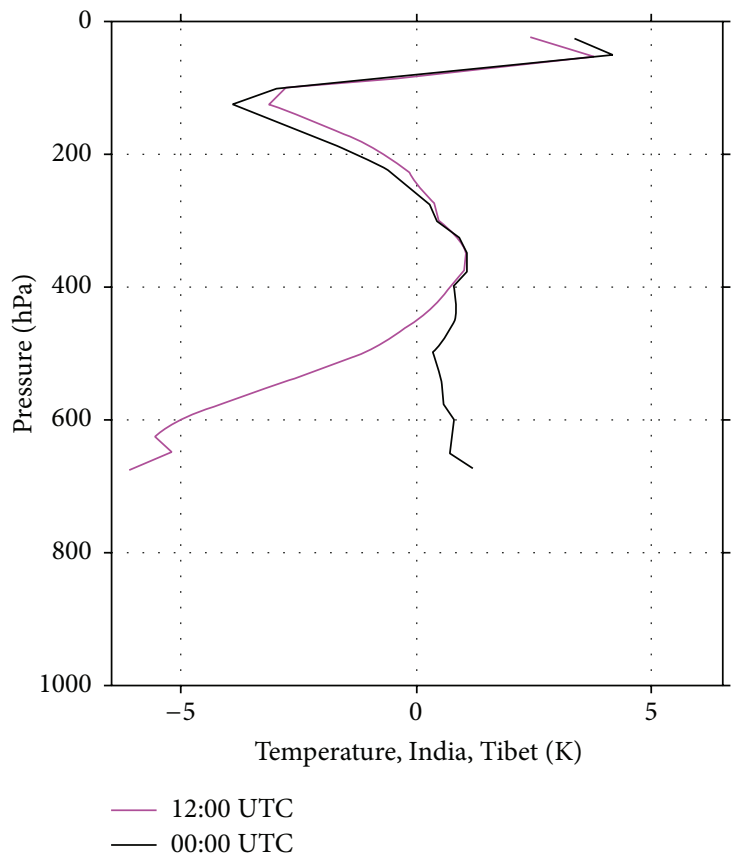

(c)

Figure 3: Thermodynamic structure from balloon soundings for June-August. (The figure is cited from Boos and Kuang [22].)

especially in spring and summer, while the land surface temperatures are rising in spring, summer, and winter, and $T_{s}$ in autumn remains unchanged. Moreover, the rising trend of $T_{s}$ is more obvious in winter. The increasing rate of $T_{s}$ in winter is greater than that in summer, while the rising trend of $T_{a}$ in summer is more remarkable than that in winter. On the other hand, the values of $T_{s}$ are always greater than that of $T_{a}$, except for several winters. It indicates that the land surface is a long-term heat source for the atmosphere. Similarly, Figure 5 shows the interannual variations of annual mean wind speed and soil moisture in each season. By comparing Figures 4 and 5, the impacts of wind speed and soil moisture on temperatures are revealed. In the winter of 2006, both $T_{s}$ and $T_{a}$ reached their maximum values $-7.38^{\circ} \mathrm{C}$ and $-8.13^{\circ} \mathrm{C}$, while the value of wind speed was the greatest and the soil moisture value was the lowest. In 2008, the values of $T_{s}$ and $T_{a}$ were down to the bottom, especially in summer and autumn. Meanwhile, the value of wind speed was lower than the average value and the soil moisture value was greater than its mean value. It can be seen from the analysis that the changes 


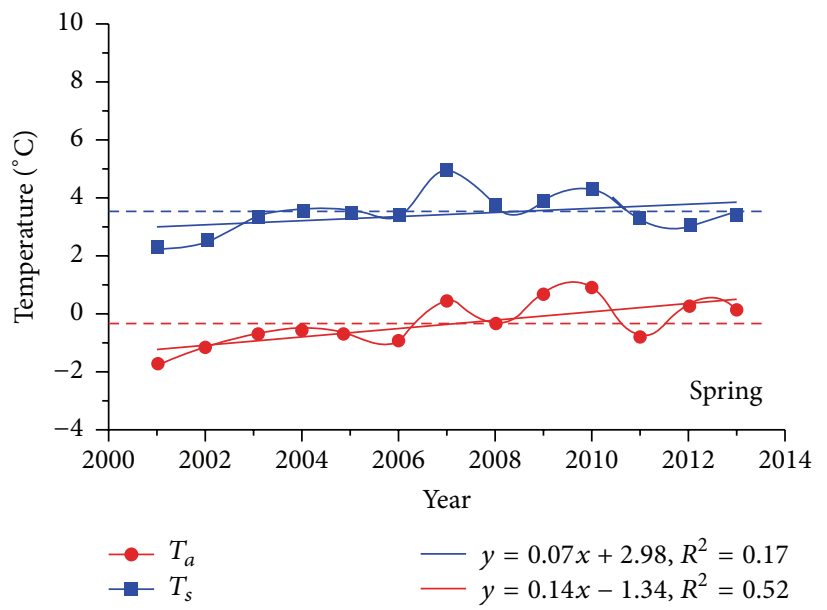

(a)

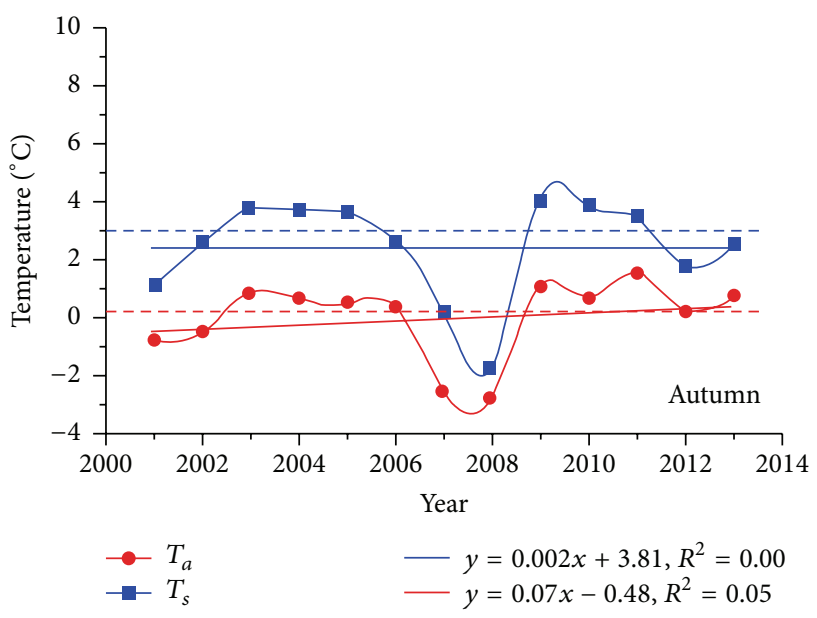

(c)

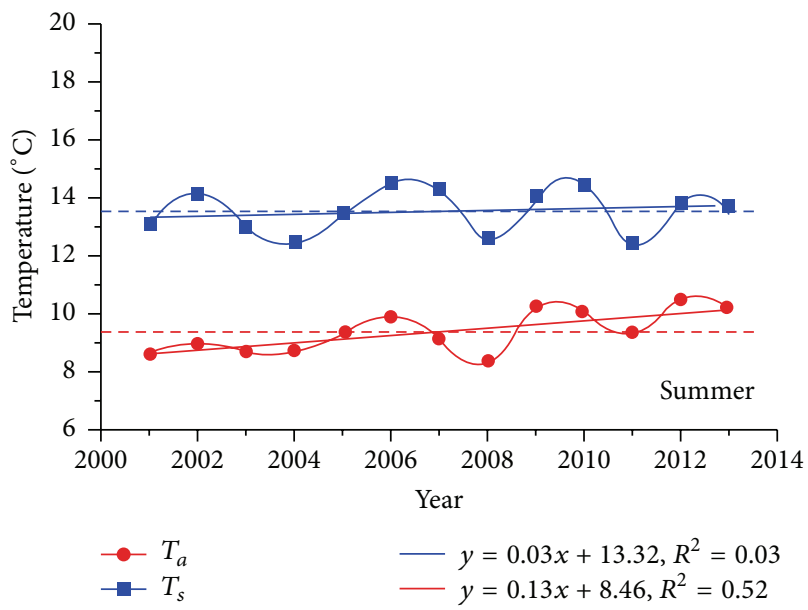

(b)

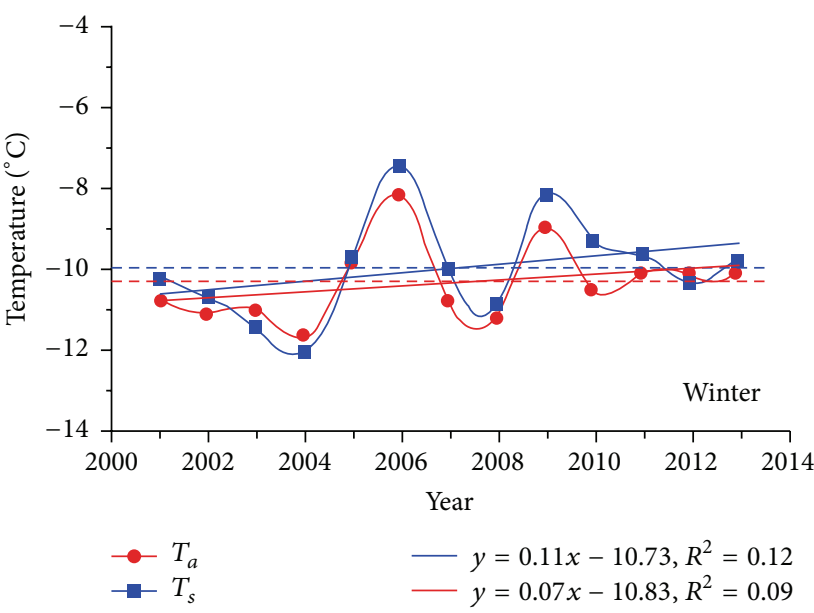

(d)

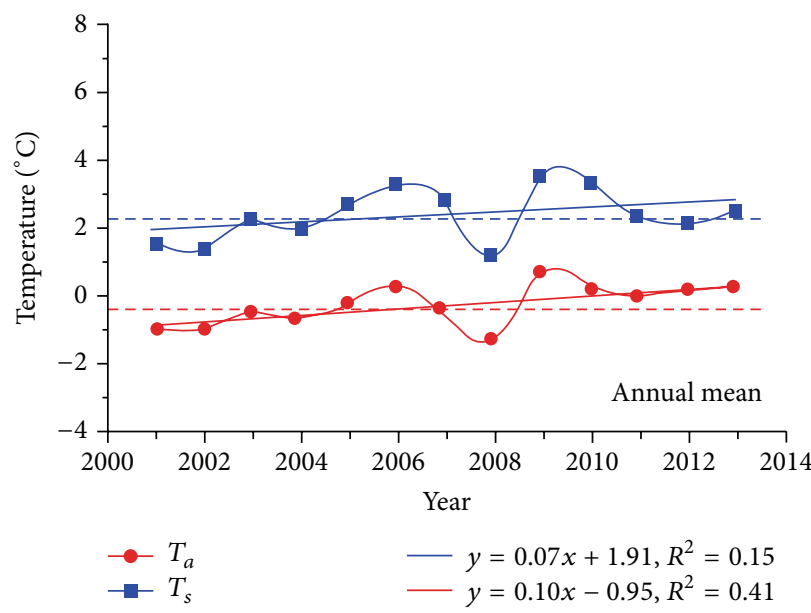

(e)

FIGURE 4: Averaged land surface temperature and air temperature change curves for seasons and years at BJ (curved lines are observed values, and straight lines are liner trend). 


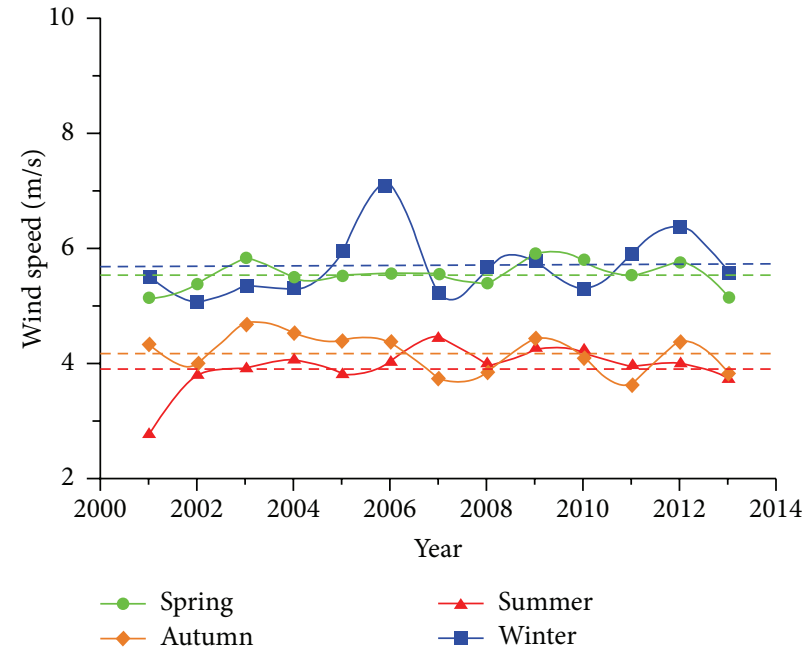

(a)

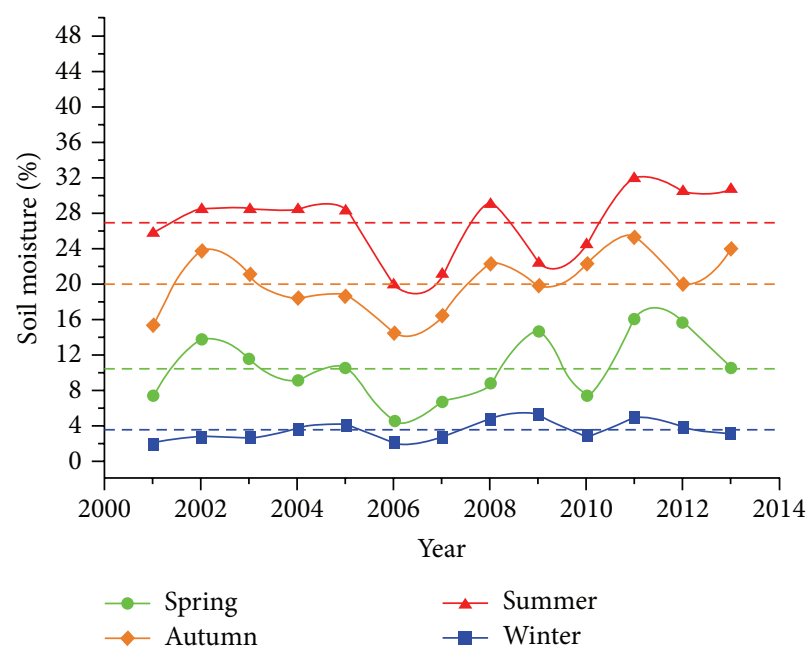

(b)

FIGURE 5: The interannual variation of wind speed and soil moisture in each season at BJ.

of wind speed and soil moisture make the difference to the temperatures on the Tibetan Plateau.

In addition, according to some researches [26, 27], El Nino and La Nina phenomenon separately occurred in 2006 and 2008. Based on some analysis [28], the surface heating field in the Tibetan Plateau has an increasing trend in El Nino year and weakens in La Nina year. Based on the above analysis, in El Nino year, the values of $T_{s}, T_{a}$ and wind speed are greater than the averaged values, and the soil moisture values are lower than the averaged, while in La Nina year, the values of $T_{s}, T_{a}$ and wind speed are less than the averaged values, and the soil moisture values are greater than the averaged. The variation of the previous surface heating field is a strong signal for the prediction of summer drought-flood anomalies at the east side of the Tibetan Plateau [29, 30]. It is thus clear that long-term observations in the Tibetan Plateau exert an important influence on the regional and global climate prediction.

3.3. Daily Observations at Different Sites. For the sake of monitoring the weather changes, a number of autoweather stations (AWSs) were set up in the Tibetan Plateau. Figure 6 shows the diurnal variations of $T_{s}$ and $T_{a}$ in D105, NPAM, and $\mathrm{BJ}$ stations mentioned in part 2, three stations in the Northern Tibetan Plateau. As can be seen from the figure, the variation trends are similar at all sites. $T_{s}$ and $T_{a}$ change significantly from daytime to nighttime; the fluctuation is larger in daytime than that in nighttime. Averagely, $T_{s}$ reaches the peak value at 14:00, while $T_{a}$ gets the maximum at 16:0018:00. Obviously, the $T_{a}$ diurnal variation falls behind $T_{s}$, and it is closely bound up with the solar radiation. Furthermore, the diurnal variation is various in different seasons, and what causes the differences may be the East and South Asian monsoon. The land surface in the plateau is relatively dry with less cloud cover and increasing solar radiation in spring, which is before the summer monsoon onset, so the surface is cooled rapidly during the night and heated fast during the day. It can explain why the temperatures get the greatest diurnal change in spring. With precipitation increasing more, the soil moisture is growing in summer and autumn, which are after the monsoon onset, and the temperatures diurnal variation is the lowest. Besides, the changes are different in different latitudes and underlying surfaces. The diurnal variation and difference of $T_{s}$ and $T_{a}$ in D105, which is mainly covered by marsh, are less than that of NPAM and BJ with grassy marshland. The effect of $T_{a}$ lagging behind $T_{s}$ can give some information for the daily maximum air temperature forecast.

The process of making weather forecast consists of observation, data acquisition, data processing, data analysis, and forecast. All of them are based on the observation, and surface observation is absolutely necessary and it provides initial and reference value for the numerical forecasting. It is obvious that daily observation has an effect on weather forecast in the Northern Tibetan Plateau.

\section{Conclusions}

The underlying surface in the Tibetan Plateau is complex and heterogeneous, and it makes all the difference to the East Asian and even global climate change. So based on the in situ measurements, weather and climate prediction is dependable and convincing. As the first-hand data, data from weather stations are widely used to validate the satellite data and model data for studying climate changes. And in situ measurements are essential to the climate and weather forecast.

Long-term observations in the Tibetan Plateau exert an important influence on the regional and global climate prediction. In the Northern Tibetan Plateau, $T_{s}$ and $T_{a}$ have been climbing since 2001, and the change trend of $T_{a}$ always keeps pace with that of $T_{s}$, but the uptrend of $T_{a}$ is more obvious than that of $T_{s}$, especially in spring. Compared with 

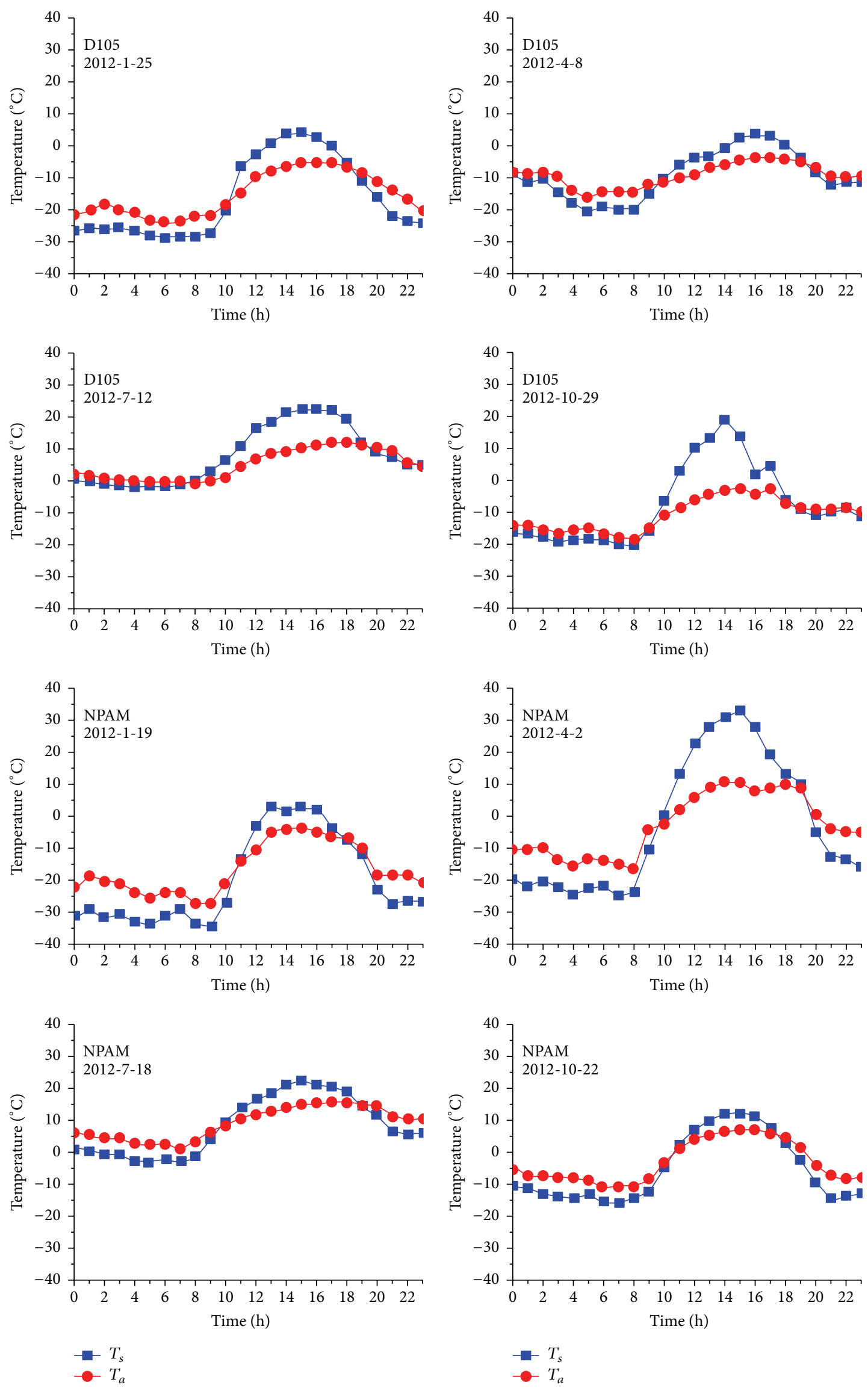

Figure 6: Continued. 

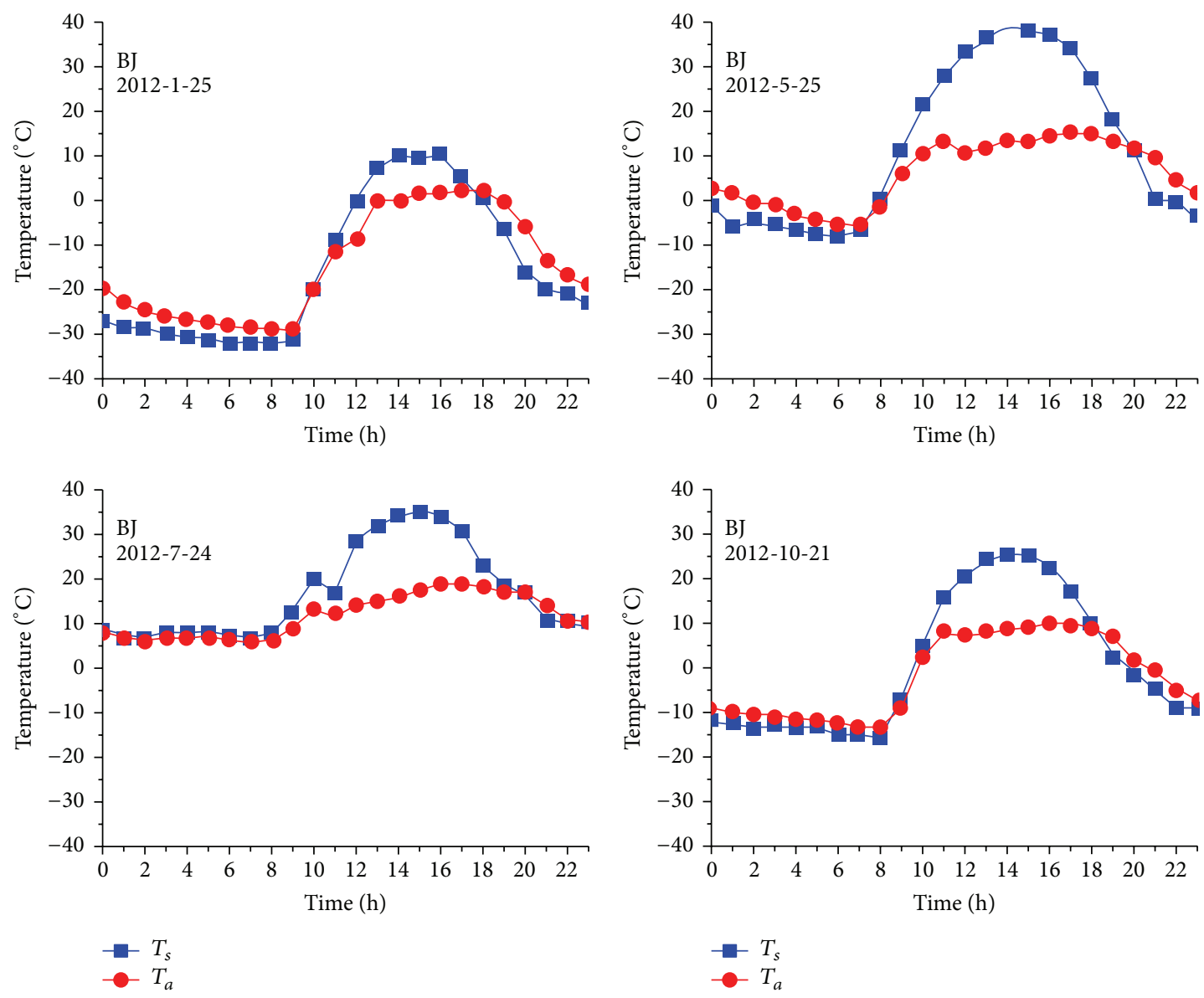

Figure 6: The diurnal variation of land surface temperature $\left(T_{s}\right)$ and air temperature $\left(T_{a}\right)$ in typical clear days in different seasons at D105/NPAM/BJ.

the global warming rate with $0.12^{\circ} \mathrm{C} / 10 \mathrm{a}$ over the past 60 years, the warming rate in the Northern Tibetan Plateau over the past ten years is greater than that in global areas. In El Nino year, the values of $T_{s}, T_{a}$ and wind speed are greater than the averaged values, and the soil moisture values are lower than the averaged, while the contrary is the case in La Nina year.

The daily variations of $T_{s}$ and $T_{a}$ at all sites have similar trend, with obvious changes in the daytime and no significant changes in the nighttime. $T_{a}$ changes lag behind that of $T_{s}$. The diurnal variations of $T_{s}$ and $T_{a}$ are the greatest in spring and are less in summer and autumn. The diurnal variation in the area with drier underlying surface is more obvious than that in the area with moist surface.

According to these observations, amount of weather and climate research in the plateau can be done continuously. As the foundation of climate prediction, long-term meteorological observations are worthy to be paid more attention.

\section{Conflict of Interests}

The authors declare no conflict of interests.

\section{Acknowledgments}

This study was funded by CAS "Hundred Talent" program (Dr. Weiqiang Ma), National Natural Science Foundation of China (NSFC) (41375009, 91337212, 41275010, and 41275028). Special thanks are given to the anonymous reviewers and the editor for very constructive comments. The authors also thank all the participations for their very hard field work during the field observations in Tibetan Plateau.

\section{References}

[1] D. Ye and Y. Gao, Meteorology of Qinghai-Xizang Plateau, Chinese Science Press, Beijing, China, 1979.

[2] Y. Duzheng, "The progress of atmosphere science research in China in recent years," Scientia Atmospherica Sinica, vol. 3, no. 3, pp. 195-202, 1979.

[3] G. Wu and Y. Zhang, "Tibetan Plateau forcing and the timing of the monsoon onset over South Asia and the South China Sea," Monthly Weather Review, vol. 126, no. 4, pp. 913-927, 1998.

[4] P. Zhao and L. Chen, "Climatic features of atmospheric heat source/sink over the Qinghai-Xizang Plateau in 35 years and its 
relation to rainfall in China," Science in China, Series D: Earth Sciences, vol. 44, no. 9, pp. 858-864, 2001.

[5] Z. Jijia, Z. Baozhen, Z. Fukang et al., Advances on QinghaiXizang Plateau Meteorology Research, Chinese Science Press, Beijing, China, 1988.

[6] Z. Qian and Y. Jiao, "Advances and problems on Qinghai-Xizang plateau meteorology research," Advances in Earth Sciences, vol. 12, no. 3, pp. 207-216, 1996.

[7] G. Ji, L. Yao, F. Yuan et al., “The characteristics of the surface and atmospheric heating fields over the Qinghai-Xizang Plateau in winter of 1982," Chinese Sciences (B), no. 3, pp. 214-224, 1986.

[8] G. Ji, M. Pu, and Y. Xi, "The characteristics of the surface and atmospheric heating fields over the Qinghai-Xizang Plateau in summer of 1983," Plateau Meteorology, vol. 5, no. 2, pp. 155-166, 1986.

[9] J. I. Guoliang, G. U. Benwen, and L. V. Lanzhi, "Characteristics of atmospheric heating field over Northern Qinghai-Xizang plateau," Plateau Meteorology, vol. 21, no. 3, pp. 238-242, 2002.

[10] X. Xu and L. Chen, "Advances of the study on Tibetan Plateau experiment of atmosphere sciences," Journal of Applied Meteorology, vol. 17, no. 6, pp. 758-772, 2006.

[11] Y. Ma, T. Yao, and J. Wang, "Experimental study of energy and water cycle in Tibetan Plateau-the progress introduction on the study of GAME/Tibet and CAMP/Tibet," Plateau Meteorology, vol. 25, no. 2, pp. 344-351, 2006.

[12] Y. Ma, L. Zhong, Z. Su, H. Ishikawa, M. Menenti, and T. Koike, "Determination of regional distributions and seasonal variations of land surface heat fluxes from Landsat-7 Enhanced Thematic Mapper data over the central Tibetan Plateau area," Journal of Geophysical Research D: Atmospheres, vol. 111, no. 10, Article ID D10305, 2006.

[13] M. Wenbin and L. Bin, "Review and prospect on the application of meteorological satellite data over Tibetan Plateau in the past 20 years," Plateau and Mountain Meteorology Research, vol. 31, no. 3, pp. 83-88, 2011.

[14] M. Abe, A. Kitoh, and T. Yasunari, "An evolution of the Asian summer monsoon associated with Mountain upliftsimulation with the MRI atmosphere-ocean coupled GCM," Journal of the Meteorological Society of Japan, vol. 81, no. 5, pp. 909-933, 2003.

[15] G. Wu, Y. Liu, B. He, Q. Bao, A. Duan, and F.-F. Jin, “Thermal controls on the Asian summer monsoon," Scientific Reports, vol. 2, article 404, 2012.

[16] M. Weiqiang, M. Yaoming, L. Maoshan et al., "Seasonal variation on land surface energy budget and energy balance components in the Northern Tibetan Plateau," Journal of Glaciology and Geocryology, vol. 27, no. 5, pp. 673-679, 2005.

[17] M.-F. Huang, X.-F. Xing, S.-H. Liu, and S.-M. Liu, "Study on the method obtaining the three elements for the retrieval of the surface temperature based on infrared radiometer," Arid Land Geography, vol. 28, no. 4, pp. 541-547, 2005.

[18] L. Chao, W. Heli, L. Houtong et al., "Effect of downwelling atmospheric radiation on grass land surface temperature," Journal of Atmospheric and Environmental Optics, vol. 3, no. 6, pp. 407-414, 2008.

[19] W. He, H. Chen, Q. Sun, and M. Wang, "The characteristics of microwave surface emissivity over Tibetan plateau," Remote Sensing Technology and Application, vol. 26, no. 6, pp. 735-741, 2011.

[20] A. A. Van De Griend and M. Owe, "On the relationship between thermal emissivity and the normalized difference vegetation index for natural surfaces," International Journal of Remote Sensing, vol. 14, no. 6, pp. 1119-1131, 1993.

[21] H. Sun, Y. Chen, A. Gong, X. Zhao, W. Zhan, and M. Wang, "Estimating mean air temperature using MODIS day and night land surface temperatures," Theoretical and Applied Climatology, vol. 118, no. 1-2, pp. 81-92, 2014.

[22] W. R. Boos and Z. Kuang, "Dominant control of the South Asian monsoon by orographic insulation versus plateau heating," Nature, vol. 463, no. 7278, pp. 218-222, 2010.

[23] IPCC, Fifth Assessment Report, Climate Change 2013: The Physical Science Basis: Summary for Policymakers, IPCC, 2013.

[24] Q. Dahe and T. Stocker, "Highlight of the IPCC working group I fifth assessment report," Progressus Inquisitiones de Mutatione Climatis, vol. 10, no. 1, pp. 1-6, 2014.

[25] S. Yongping and W. Guoya, "Key findings and assessment results of IPCC WGI fifth assessment report," Jounal of Glaciology and Geocryology, vol. 35, no. 5, pp. 1068-1076, 2013.

[26] Y.-Y. Sun, J.-Y. Liu, H.-F. Tsai, C.-H. Lin, and Y.-H. Kuo, “The equatorial El Nino-Southern oscillation signatures observed by FORMOSAT-3/COSMIC from July 2006 to January 2012," Terrestrial, Atmospheric and Oceanic Sciences, vol. 25, no. 4, pp. 545-558, 2014.

[27] F. Zheng and J. Zhu, "Roles of initial ocean surface and subsurface states on successfully predicting 2006-2007 El Niño with an intermediate coupled model," Ocean Science, vol. 11, no. 1, pp. 187-194, 2015.

[28] L. Dongliang, H. Jinhai, T. Xu et al., “The relationship between the intensity of surface heating fields over the Qinghai-Xizang plateau and ENSO cycle," Plateau Meteorology, vol. 26, no. 1, pp. 39-46, 2007.

[29] C. Wen, "Impacts of El Nino and La Nina on the cycle of the East Asian winter and summer monsoon," Chinese Journal of Atmospheric Sciences, vol. 26, no. 5, pp. 595-610, 2002.

[30] C. Hongbin and F. Xuehua, "Some extreme events of weather, climate and related phenomena in 2008," Climatic and Environmental Research, vol. 14, no. 3, pp. 329-340, 2009. 

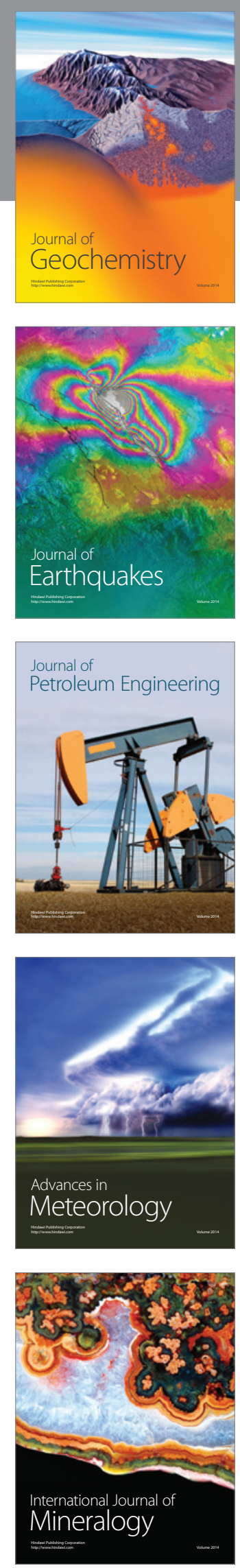
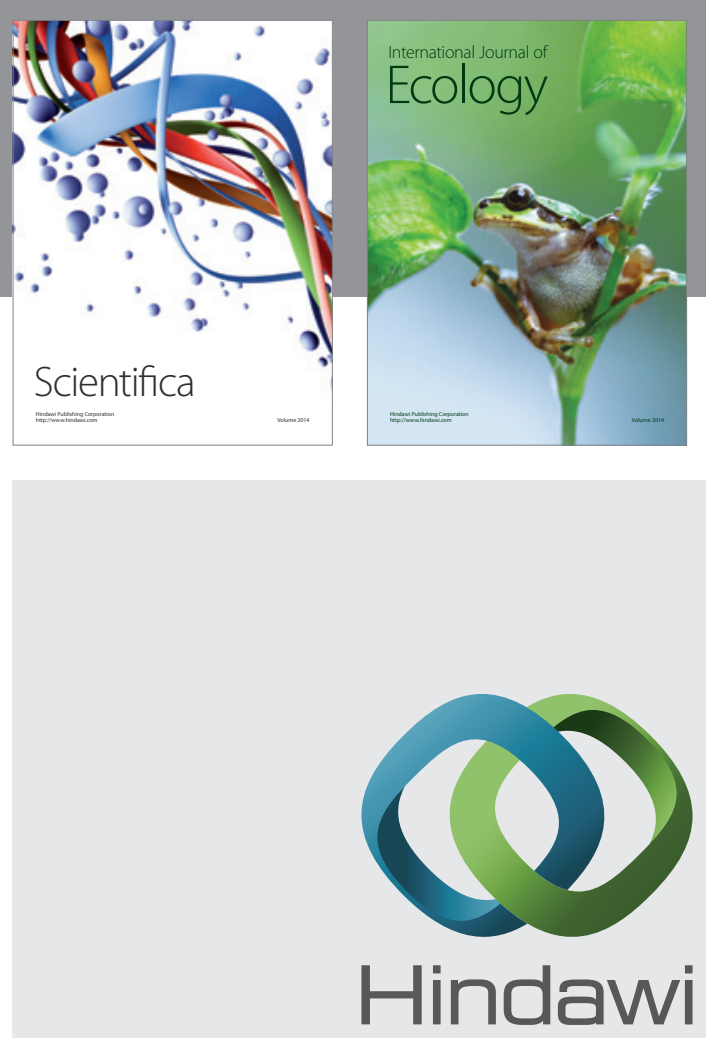

Submit your manuscripts at

http://www.hindawi.com
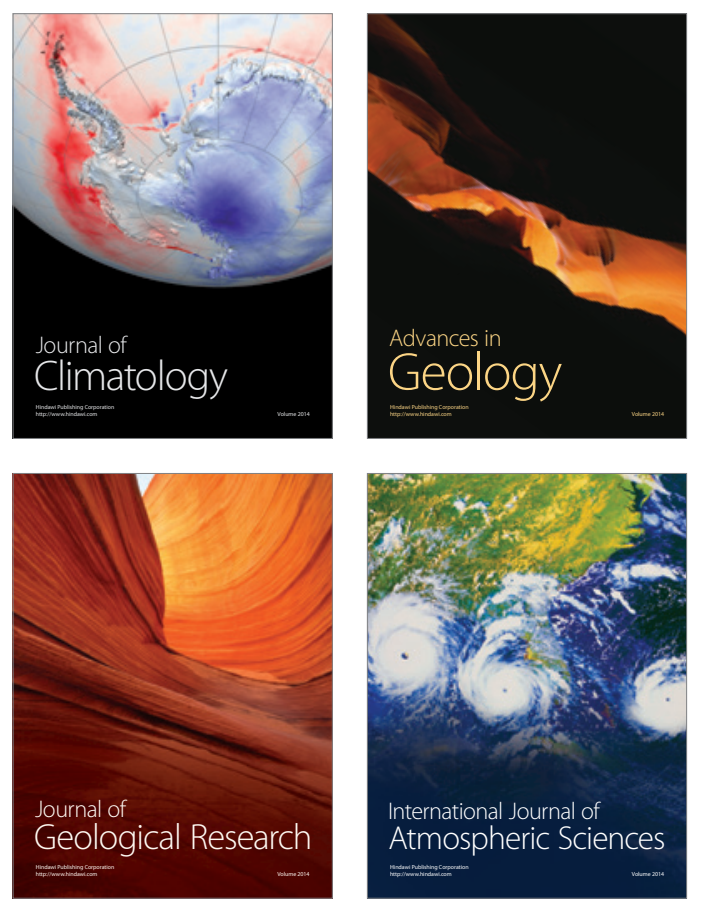

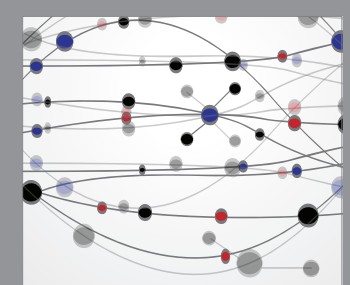

The Scientific

\section{World Journal}
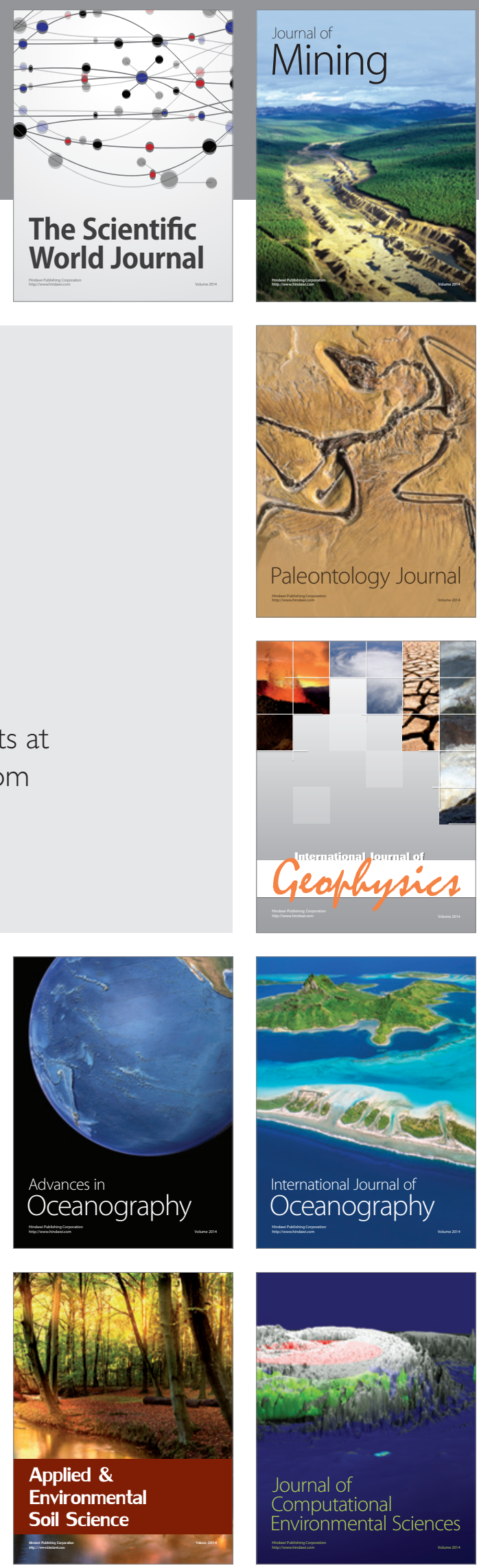